Revista de Estudios Histórico-Jurídicos

[Sección historia de las instituciones]

XLIII (Valparaíso, Chile, 2021)

[pp. 751-777]

\title{
¿UNA DISCUSIÓN RESUCITADA? El CASO FORTUITO INCOMPLETO Y LOS ANTECEDENTES HISTÓRICOS DEL VERSARI IN RE ILLICITA EN CHILE*
}

[A resurrected discussion? The incomplete fortuitous case and the historical background of the versari in re illicita maxim in Chile]

\author{
Tatiana Vargas Pinto** \\ Universidad de los Andes, Chile
}

\begin{abstract}
RESUMEN
En este estudio se destaca la relevancia actual de la máxima versari in re illicita frente al caso fortuito incompleto, pero también ante frecuentes comportamientos ilícitos en los que se imputan resultados más graves no buscados, como conductas lesivas que producen la muerte de otro. Asimismo, se realiza un primer cuestionamiento de la concepción objetiva tradicional del versari, especialmente desde consideraciones históricas en el contexto jurídico-penal chileno.

Palabras clave

Versari - responsabilidad objetiva caso fortuito - preterintención.
\end{abstract}

\begin{abstract}
This study emphasizes the current relevance of the versari in re illicita in case of the incomplete fortuitous event, but also because of frequent illicit actions in which more serious and unintended results are imputed, such as harmful behaviors that cause the death of another. Likewise, it offers a first objection to the traditional objective conception of Versari, especially from an historical perspective in the Chilean legal-criminal context.

KEY WORDS

Versari - strict liability - fortuitous evento - praeter intentionem.
\end{abstract}

RECIBIDO el 30 de abril de 2020 y ACEPTADO el 13 de noviembre 2020

* Tabla de abreviaturas. ADPCP.: Anuario de Derecho Penal y Ciencias Penales; GS.: Der Gerichtssaal; L. Rev.: Law Review; RECPC.: Revista Electrónica de Ciencia Penaly Criminología; REJ.: Revista Estudios de la Justicia; STOP: Tribunal Oral en lo Penal.

** Doctora en Derecho, Profesora de Derecho Penal, Universidad de los Andes, Mons. Álvaro del Portillo 12.455, Las Condes, Santiago de Chile; tatianavp@uandes.cl. ORCID 0000-0002-0728-3846. Este estudio se realiza en el contexto del proyecto Fondecyt Regular $\mathrm{N}^{\mathrm{o}} 1181621$. 


\section{EL PROBLEMA GENERAL DEL VERSARI EN EL DERECHO PENAL CHILENO}

La máxima del versari in re illicita, de origen canónico ${ }^{1}$, no genera aparentemente problemas en la regulación penal chilena ni en la dogmática nacional por su general rechazo. La objeción surge de inmediato ante los principios de culpabilidad y de responsabilidad penal subjetiva ${ }^{2}$. Ello parece, a primera vista, restar relevancia a cualquier análisis o discusión al respecto. En realidad, no hay unanimidad acerca de este aforismo en la doctrina, ni en sus antecedentes históricos, aunque no se advierta expresamente.

Normalmente, se entiende que el versari supone asignar a quien realiza una conducta ilícita todas las consecuencias que de ella se deriven, aunque no fueren intentadas ni aun previsibles ${ }^{3}$. Aparece como un principio de imputación sobre la base de exigencias puramente objetivas. Como se apuntó, el rechazo global se explica con base en principios penales básicos ${ }^{4}$, que niegan todo atisbo de responsabilidad penal objetiva.

Suelen citarse como supuestos de versari en la regulación chilena el tipo penal de incendio que contempla explosiones y que por ellas se causa la muerte o lesiones graves de "personas que se hallaren a cualquier distancia del lugar del siniestro" (art. 474, inciso $3^{\circ}$ del CP) $)^{5}$. El caso se distingue de las hipótesis consagradas en los primeros incisos de la disposición, que solo se remiten al incendio -no a

${ }^{1}$ Corpus Juris Canonici, Presbyterum, tit. cap. 7-10, 12, 13, 14, 19, 23; Continebatur, cap. 8; Sexto de las Decretales. La máxima tiene antecedentes en el Decreto de Graciano, en PAPIENSE, Bernardo, Summa Decretalium (Ratisbonae, 1860). En general, von BAR, Carl, Gesetz und Schuld (Guttentag, Berlín, 1907), Bd II, S 115; KuTtNER, Stephan, Kanonistische Schuldlehre von Gratian bis auf die Dekretalen Gregors IX.: Systematisch auf Grund der Quellen handschriftlichen dargestellt (Città del Vaticano, 1935), p. 185, 277; Jescheck, Hans-Heinrich; Weigend, Thomas, Lebrbuch des Strafrechts: Allgemeiner Teil (Duncke r \& Humboldt, Berlín, 1996), \$26 II. 1. A). PEREDA, Julián, El 'versari in re illicita' en la doctrina y en el Código Penal. Solución suareciana (Reus, Madrid, 1948), p. 37 , cree que su origen es muy anterior, que ya aparece con claridad en concilios del siglo IX. Igualmente, observaremos brevemente que las nociones de los primeros canonistas no coinciden con las que sostuvieron otros posteriores.

${ }^{2}$ Exigir ambos principios refuerza la necesidad de consideraciones subjetivas. Podría decirse que el principio de responsabilidad subjetiva es más claro. La culpabilidad, como principio, puede hacer una referencia global a elementos subjetivos, aunque -como categoría- los integra en un juicio de imputación personal, cuya estructura subjetiva puede cambiar. Destacan la culpabilidad precisamente ante riesgos de atribución objetiva, Rodríguez, Luis; DE LA FuENTE, Felipe, El principio de culpabilidad en la Constitución de 1980, en Revista de Derecho de la Universidad Católica de Valparaíso, 13 (1989-1990) pp. 126-129. Además del rechazo de presunciones de derecho, es relevante el peligro de presunciones legales, sobre todo la discusión sobre la expresión v o l u n t a ri a en la definición de delito (art. 1), que se expondrá.

${ }^{3}$ Veremos que esta interpretación generalizada es la que se mantiene en Chile y la que se cuestiona en este estudio.

${ }^{4}$ También se objeta en términos generales su constitucionalidad por suponer una presunción de derecho, así Bascuñán, Antonio, Comentario. Corte Suprema, 20 de noviembre de 1997, en Revista de Derecho y Jurisprudencia y Gaceta de los Tribunales, 3 (1997), segunda parte, sección cuarta, p. 230.

${ }^{5}$ Así, Politoff, Sergio; Matus, Jean Pierre; Ramírez, María Cecilia, Lecciones de derecho penal. Parte general, (Santiago, Editorial Jurídica de Chile, 2004), p. 251; Garrido, Mario, Derecho penal. Parte general (4a ed., Santiago, Editorial Jurídica de Chile, 2005), II, p. 232. 
explosiones-que provoca muerte o lesiones graves de personas que se hallan en el lugar incendiado. Estas hipótesis agregan además la posibilidad de prever la presencia allí de las personas afectadas. Esas figuras admitirían un nexo subjetivo con el resultado de muerte o lesiones, dado por la previsibilidad de la presencia de las personas en los lugares incendiados y las respectivas consecuencias.

La previsibilidad de los resultados posibles suele admitirse como exigencia mínima para configurar la llamada culpa o imprudencia sin representación ${ }^{6}$. De suerte que la primera alternativa comentada y descrita en el inciso final del art. 474 , al agregar otra causa respecto de personas fuera del lugar incendiado y sin referencias subjetivas, aparece como una hipótesis de responsabilidad objetiva rechazada. Su admisión se construye como figura preterintencional, entendida en general como una conducta dolosa junto a otra culposa ${ }^{7}$. El incendio doloso de un lugar (poblado) es también una conducta peligrosa para las personas que circulan $^{8}$, cuya realización consciente admite un comportamiento imprudente. Con esta estructura puede fundarse la sanción de esta hipótesis, pero difícilmente puede explicarse la diferencia de pena.

Otros casos comprendidos como manifestaciones del versari no son tan evidentes. En algunos tipos penales que generan dudas, como el delito de abandono de menores y de personas desvalidas o el homicidio o lesiones en riña o pelea ${ }^{9}$, se explica el aumento de pena por el resultado más grave como condición objetiva de punibilidad. Como se sabe, estas condiciones no generan los problemas de estructuras que admitirían solo una vinculación objetiva entre conducta y efecto. Las condiciones responden a causas ajenas a la conducta del agente, por lo que

${ }^{6}$ Más, específicamente en el contexto médico, VARgas, Tatiana, Algunos antecedentes sobre el complejo "deber de previsión" médico, en Revista de Derecho, 30/1 (2017), pp. 360-363.

${ }^{7}$ Ver, Politoff, Sergio; Matus, Jean Pierre; Ramírez, María Cecilia, Lecciones de derecho penal. Parte especial, (2a ed., Santiago, Editorial Jurídica de Chile, 2006), pp. 107 y 108; GARrido, Mario, Derecho penal. Parte especial, (4a ed., Santiago, Editorial Jurídica de Chile, 2010), III., pp. 110 y 111; Ossandón, Magdalena, La intención de dar muerte al feto y su relevancia para la imputación objetiva y subjetiva en el delito de aborto, en Revista de Derecho Universidad Católica del Norte, 2 (2011) p. 113. Observaremos que tampoco hay tanta claridad respecto de la noción de preterintención, y en ocasiones se confunde con la cualificación por el resultado.

${ }^{8}$ Normalmente, no se hace mayor distinción respecto del nivel de peligrosidad de la conducta y la clase de imprudencia que supone. La exigencia de imprudencia no parece distinguirse de los casos anteriores contemplados en el art. 474, cuando mueren o se lesionan personas en el lugar incendiado cuya presencia se pudo prever. Si todos los casos del art. 474 suponen figuras preterintencionales construidas sobre la base de un incendio doloso con muertes o lesiones imprudentes (inconscientes), no se explica la menor penalidad de la última alternativa referida a las explosiones. La distinción de clases y grados de conocimiento de la peligrosidad no es tan ajena a consideraciones de imputación. Carrara, Francesco, Opuscoli di Diritto Criminale (Lucca, 1870), I, voz Dolo, pp. 312 y ss., criticaba la sola previsibilidad, como posibilidad de conocer riesgos, de una previsión real acreditada.

${ }^{9}$ Especialmente, Politoff, Sergio; Grisolía, Francisco; Bustos, Juan, Derecho penal. Parte especial. Delitos contra el individuo en sus condiciones físicas, $\left(2^{\mathrm{a}} \mathrm{ed}\right.$., Santiago, Editorial Jurídica Congreso, 2006), pp. 245 y ss.; Politoff, Sergio; Matus, Jean Pierre; Ramírez, María Cecilia, cit. (n. 5), pp. 154-176; Torres, Javiera, Delito de abandono de personas desvalidas, en Revista de Derecho de la Pontificia Universidad Católica de Valparaíso, 43/2 (2014), pp. 262, 264, 267, 269, 274, 281 y ss. 
no tiene injerencia ninguna clase de vínculo con el comportamiento típico, más allá de la exigencia legislativa para imponer la pena.

El reflejo más claro del versari en la legislación nacional está en el llamado c a so fortuito in com pleto, a raíz de la regulación establecida en el art. $10 \mathrm{n}^{\circ} 8 \mathrm{del} \mathrm{CP}^{10}$. Esta norma es idéntica al anterior art. $8 \mathrm{n}^{\circ} 8$ del CP español de 1973 , derogado en $1983^{11}$. No había duda en la dogmática española que esta disposición del caso fortuito consagraba el versari cuando no se daba el primero de sus requisitos ${ }^{12}$, es decir, cuando faltaba la acción lícita. El problema se traslada a la realización de una acción ilícita que igualmente produce un mal por mero accidente $y$, aun, con el debido cuidado.

La eximente no tiene lugar. Su improcedencia hacía pensar que cabía imputar todos los efectos conectados con la acción ilícita. La relación de una disposición tal vigente en Chile con el versari in re illicita $\mathrm{o}$, al menos, con su general concepción objetiva, reclama un examen especial a continuación. De hecho, un supuesto clásico de versari es el de quien tala ilegalmente un árbol con el debido cuidado, pero da muerte a un sujeto que pasó por el lugar (despejado al momento de la tala). Otro caso conocido, antiguo, es el del sujeto que se hace pasar por santo en una procesión ${ }^{13}$. Con la vestimenta y joyas del (ficticio) santo, sale en la procesión sin que los asistentes conozcan la farsa. Uno de ellos arrebata las joyas para sustraerlas a quien pasaba por santo y el susto le provoca un ataque al corazón que le causa la muerte.

Más allá de estos ejemplos históricos, los casos que se asocian a la comprensión común del versari parecen bastante más usuales, como conductas lesivas que terminan produciendo la muerte, o conductas peligrosas, como la conducción temeraria de vehículos ${ }^{14}$. En muchas ocasiones parece relevante la producción de consecuencias mayores o de otros resultados a partir de una acción ilícita, sin que ellos fueran siquiera intentados.

Los supuestos se relacionan tanto con las estructuras de preterintención como con las de cualificación por el resultado ${ }^{15}$, sin que haya tampoco definición al respecto. Hay algunos pocos casos en los que se ha esbozado el principio del versari

\footnotetext{
${ }^{10}$ Igualmente, veremos otros casos, incluso la regla del art. 1 inciso $3^{\circ}$ del CP, con la irrelevancia del mal causado a otro. Este supuesto resuelve en verdad un caso de error en el objeto, en la persona, y no de error en el golpe; de modo que se advierte la presencia de un o t r o , pero que no era a quien exactamente se proponía afectar. De allí que sea razonable la respuesta de no considerar las circunstancias agravantes y sí las atenuantes (pro reo).

${ }^{11}$ Uno de los objetivos de la reforma fue desterrar todo indicio de responsabilidad objetiva y sus manifestaciones, fundando la responsabilidad solo en dolo y culpa, Ley Orgánica 8/1983, de 25 de junio, de Reforma Urgente y Parcial del Código Penal.

${ }^{12}$ Por ejemplo, Cerezo, José, El versari in re illicita y el párrafo tercero del, artículo 340 bis a del Código Penal español, en ADPCP., 23 (1970), pp. 287 y 288.

${ }^{13}$ UaOndo, Juan de, La preterintencionalidad y el "Codex Iuris Canonici”, en Revista Española de Derecho Canónico, 7/19 (1952), p. 46.

${ }^{14}$ CANESTRARI, Stefano, La estructura del dolo eventual y las nuevas fenomenologías de riesgo (trad. castellana), en Anales de Derecho, 23 (2004), p. 77, alude a relación de esta conducción con el versari, al igual que el caso del ladrón que dispara para huir.

${ }^{15}$ Veremos que en nuestro país las figuras de preterintención se distinguen en general por la reunión de una conducta dolosa y otra imprudente respecto del mayor resultado, a diferen-
} 
para descartar la imputación de ese mayor resultado ${ }^{16}$. Los problemas de imputación son habituales, pero no hay claridad sobre los supuestos que comprende, ni certeza sobre la noción y recepción del versari in re illicita. Esto suma otra razón para indagar sobre la recepción de la máxima en el supuesto más evidente de la legislación nacional y cuestionar su sentido al menos en la dogmática nacional y desde sus orígenes.

Se afirma que el caso fortuito incompleto es una hipótesis que ilustra el problema del versar ${ }^{17}$. Sin embargo, veremos que en Chile ello no ha supuesto aceptar imputaciones por meros resultados. De igual forma, aquí se pone en jaque la usual interpretación objetiva del versari, aun desde antecedentes históricos en el contexto jurídico-penal chileno.

\section{RECEPCIÓN LEGAL Y EXAMEN DOGMÁTICO}

La máxima original versanti in re illicita etiam casus imputatur, o versanti in re illicitae imputantur omnia guae sequntor ex delicto ${ }^{18}$, se interpreta como quien actúa ilegalmente es responsable de todas las consecuencias de su conducta. La referencia a casus lleva específicamente a considerar el caso fortuito. Algunos limitan a él exclusivamente su sentido ${ }^{19}$. Sin embargo, el casus se entendió desde el derecho romano como todo lo que no era dolo ${ }^{20}$, que podía incluir la imprudencia y el caso fortuito.

Esta última consideración del casus ha primado; claro que le exención de responsabilidad se conectaba fácilmente con acciones lícitas ${ }^{21}$, muy en la línea de la actual regulación chilena y de la antigua legislación española. El casus y, específicamente, del versari se ha conectado con la doctrina del v ol u n t a r i o a c c i d e n t a 1 de Aquino. En nuestro país, Bascuñán ${ }^{22}$ relaciona el versari con una

cia de la cualificación por el resultado. Esta última motiva las objeciones por la admisión de responsabilidad objetiva, aunque la distinción no sea del todo clara.

${ }^{16}$ Así, destaca el voto disidente de la ministra Rojas en un caso complejo de riesgos para la seguridad vial en contra de un conocido deportista nacional. Recurre al versari para rechazar la inclusión de factores no dominables (noción objetiva), "de no ser así, entraríamos en terrenos propios del versari in re illicita, y hacerlo responder por todas las consecuencias que derivan de esa conducta, aún de las imprevisibles y no dominables por el agente". STOP de Santiago $\left(3^{\circ}\right)$ de 27 de junio de 2013, RUC: 0901212465-9.

${ }^{17}$ Expresamente, Polanco, Daniel, Estudio sobre la agravante del articulo 72 del Código Penal: Prevalerse de un menor de edad. Análisis de sus elementos y aplicación, en Polit. crim., 10/20 (2015), p. 599. A pesar de esta afirmación, veremos que la doctrina nacional no hace una aplicación automática de la culpa o imprudencia.

${ }^{18}$ Gardner, Martin, The Mens Rea Enigma: Observations on the Role of Motive in the Criminal Law Past and Present, en Utah L. Rev., 3 (1993), p. 705.

${ }^{19}$ Así, Rodríguez Mourullo, Gonzalo, Hacia una nueva interpretación de la eximente del caso fortuito, en ADPCP., 16 (1963), p. 273.

${ }^{20}$ Ver Pessina, Enrique, Elementos de derecho penal (trad. cast., Madrid, Imprenta de la Revista de la Legislación, 1892), p. 213.

${ }^{21}$ En el ámbito español se entendía claramente que el caso fortuito no era punible si provenía de una acción lícita, ver SÁNCHEZ-Tejerina, Isaías, Derecho penal español ( $5^{a}$ ed., Madrid, Imprenta y Litografía Juan Bravo, 1950), I, p. 302.

${ }^{22}$ Bascuñán, Antonio, cit. (n. 4), pp. 229 y 230. 
parte de esa doctrina. Manifiesta que según el i n v o l u n t a ri o a c c i d e n t a l se admite responsabilidad por un resultado imprevisto en dos supuestos ${ }^{23}$ : cuando los efectos son causados por una acción en sí misma ilícita y cuando la acción es lícita, pero se realiza sin el cuidado debido. Es claro que la primera opción, la acción ilícita, es la que puede tener relación con el versari in re illicita, como señala Bascuñán. Entiende que solo esa parte de la doctrina desarrollada por la teología moral es inconstitucional al infringir la prohibición que existe en Chile de presumir de derecho la responsabilidad penal. La crítica se basa en la imputación de estos supuestos. Santo Tomás no sólo se queda en el plano moral, sino que tampoco llega a afirmar imputaciones por imprevisión, a pesar de una acción ilícita.

Llama la atención que el voluntario accidental se refiera a efectos lesivos imprevistos que se imputan en dos supuestos, pero solo uno de ellos se critique. Se comprende que Bascuñán no critique la alternativa referida a acciones lícitas realizadas sin el debido cuidado, por la determinación de una conducta imprudente. Esta verificación ya no puede ser considerada un supuesto imprevisto y, en tal sentido, tampoco podría ser v olu n ta ri o a c c id e n tal. Entonces, parece que solo uno de los casos corresponde realmente a esa doctrina. Sin embargo, una acción e n sí mis ma ilícita no es cualquier acción ilícita; es aquella que lo es por naturaleza, por su objeto ${ }^{24}$. El nivel de peligrosidad que ella supondría no parece vincularse con toda ilicitud, como una infracción de reglamentos ${ }^{25}$. Se omite el cuestionamiento sobre la real imprevisión de un efecto que viene de una acción en sí misma ilícita.

No está de más advertir algunas consideraciones sobre la doctrina de santo Tomás al respecto, a quien se asigna la determinación de responsabilidad por un resultado no querido, pero no necesariamente no previsto. Son cuestiones distintas. Así, destaca el examen de la cosa ilícita en sí misma, como aquella que por su naturaleza es peligrosa y via quaedam ad homicidium ${ }^{26}$.

\footnotetext{
${ }^{23}$ Esto es discutible en la doctrina de santo Tomás, que rechaza imputación por ignorancia y reconoce una voluntad disminuida para imputar un pecado posterior a un acto ilícito. Así, AQuino, Tomás de, Summa Theologica, II-II, q. 150 a. 4 co.

${ }^{24}$ Es cierto que Tomás de Aquino las considera ilícitas por su objeto, con independencia de las circunstancias y fines. Sin embargo, la clase de objeto es relevante para la elección y, por tanto, para el conocimiento.

${ }^{25}$ Incluso la entidad de ciertas conductas delictivas destaca su ilicitud, pero ella no parece definirla en sí misma, ni alcanzar otros efectos, como lesiones leves que terminan produciendo la muerte. Esos efectos se conectan causalmente y podría establecerse incluso una relación de riesgo entre la conducta peligrosa y la muerte. La proporcionalidad entre conducta y efecto es clave. El problema se advierte específicamente respecto de la imputación subjetiva, a partir de hechos. Es cierto que podría no imputarse el resultado muerte desde el fin de la norma infringida, pero los alcances de la norma no se determinan sólo objetivamente. Un análisis meramente objetivo conlleva el peligro de ampliar atribuciones normativas. No está demás recordar el rescate de la imputación objetiva de Honig, Richard, Causalidad e imputación objetiva, en SancinetTi, Marcelo (comp.), Causalidad, riesgo e imputación (trad. castellana, Buenos Aires, Hammurabi, 2009), pp. 115-120, que no deja el análisis subjetivo.

${ }^{26}$ Vío, Tomás de (Cayetano), Commentarium in Summa S. Thomae, en Angelici Doctoris S. Thomae Aquinatis, Summa theologica, cum commentariis Thomae de Vio Card. Cajetani, et elucidationibus litteralibus P. Seraphini Capponi a Porrecta, (Roma, s./ed., 1773), ad 2a 2ae, q. LXIV, a. VIII.
} 
Un ejemplo actual, pero relevante históricamente, puede servir para ilustrar el problema de las acciones ilícitas y peligrosas. Se trata de la infracción de normas contempladas en situaciones de pandemia. Puede configurarse una acción ilícita si se infringen reglas sanitarias, como no cumplir un toque de queda o una cuarentena; pero ello no necesariamente supone la existencia de un delito, incluso si se hace referencia a estas reglas, como el art. 318 del Código Penal chileno ${ }^{27}$. Este delito exige, además del incumplimiento de esas normas, el peligro para la salud pública. Tal peligro distingue la ilicitud de la conducta de otras que no requieren afectar situaciones valoradas para aplicarse ${ }^{28}$.

Esta figura establece la infracción de normas de higiene o salubridad debidamente publicadas en época de catástrofe, pandemia o contagio, que pone en peligro la salud pública. Es un delito de puesta en peligro abstracto porque ha de suponer un riesgo real ${ }^{29}$, aunque no existan personas o bienes individuales en contacto directo con la conducta. La figura ha generado discusión sobre la clase de peligro, si es abstracto o concreto, sin embargo, es claro que han de rechazarse los delitos formales.

En el caso de contagio habría una puesta en peligro abstracta, una situación de amenaza real, aunque no existan personas en contacto, mientras exista la posibilidad de que lo estén. Este peligro falta en la conducta de quien no está contagiado. Igualmente, el dolo o la clase de conocimiento es distinta. Cuando el infractor no está contagiado también existe cierto riesgo, una peligrosidad general, si hay la posibilidad de que lo esté o de que llegue a contagiarse por otros que lo están o no lo saben por ser asintomáticos. En caso de infractores asintomáticos, el peligro objetivo es igual al generado por quien sabe que está contagiado, pero el conocimiento del agente es básico para dirigirle la norma de conducta, también las normas de cuidado, aunque el conocimiento se dirija a la peligrosidad de la conducta y no al resultado de lesión ${ }^{30}$.

${ }^{27}$ Art. 318. "El que pusiere en peligro la salud pública por infracción de las reglas bigiénicas o de salubridad, debidamente publicadas por la autoridad, en tiempo de catástrofe, epidemia o contagio, será penado con presidio menor en su grado minimo o multa de seis a veinte unidades tributarias mensuales".

${ }^{28}$ En Chile, por ejemplo, el art. 174 del Código Sanitario sanciona con multa la infracción de disposiciones de la autoridad de salud.

${ }^{29}$ Hasta junio de 2020 se discutió si el delito del art. 318 era un delito de peligro concreto (defensores) o un delito de peligro abstracto (fiscales). En esa fecha, la introducción del nuevo 318 bis supuso admitir que el art. 318 es un delito de peligro abstracto, aunque con diversas concepciones sobre esta clase de delitos. Así, ver Londoño, Fernando, Art. 318, en Couso, Jaime; Hernández, Héctor (dirs.), Código penal comentado. Parte especial. Libro segundo, título VI (arts. 261 a 341) (Santiago, Thomson-Reuters, 2019), pp. 519 y 520. Aquí se parte de la base de una noción de peligro autónomo respecto de bienes colectivos (que puede o no vincularse con bienes individuales), una puesta en peligro abstracta, pero que supone una situación de amenaza real por la creación de una situación de riesgo incontrolable ex post, que puede alcanzar a cualquiera. Así, Vargas, Tatiana, Delitos de peligro abstracto y resultado. Determinación de la incertidumbre penalmente relevante (Pamplona, Thomson-Aranzadi, 2007), pp. 331 y ss.

${ }^{30}$ Rodríguez y De la Fuente, cit. (n. 2), p. 126, destacan dentro del principio de culpabilidad el responder por aquello que está dentro de sus posibilidades de previsión. Como se sabe, en la llamada culpa o imprudencia consciente el agente conoce la peligrosidad de la conducta y el resultado de peligro (más general o abstracto, a diferencia del dolo eventual). En la llamada 
Interesa aquí no solo debatir la asunción de responsabilidad por consecuencias imprevistas desde esa doctrina. También es relevante preguntarse por la afirmación de responsabilidad conectada con el caso fortuito incompleto en la legislación chilena, que se refiere precisamente a acciones ilícitas relacionadas con el accidente y con la imprudencia, identificado con el versari. Se observa aquí la influencia de la doctrina tomista y la necesidad de examinar además el desarrollo del versari por los juristas escolásticos.

\section{El caso fortuito incompleto}

El caso fortuito se contempla como eximente de responsabilidad penal en el art. $10 \mathrm{n}^{\circ} 8$ del Código Penal chileno del siguiente modo: está exento de responsabilidad el que "con ocasión de ejecutar un acto lícito, con la debida diligencia, causa un mal por mero accidente". La dificultad surge cuando se trata de una acción ilícita y se dan los demás requisitos, es decir, con la debida diligencia, produce un mal por mero accidente. Es el caso fortuito incompleto, pues falta la acción lícita inicial.

La falta del acto lícito impide eximir de responsabilidad y se presenta el problema de imputación por resultados causados a partir de una acción típica e ilícita, pero producidos por mero accidente y con el debido cuidado. Incluso, no parece procedente la atenuante de responsabilidad que existe en la legislación chilena cuando hay eximentes incompletas (art. $11 \mathrm{n}^{\circ} 1^{31}$ ). Para que proceda bajar la pena se requiere al menos la presencia del elemento esencial, que es aparentemente la realización de una acción lícita. El que realiza una acción ilícita tendría entonces responsabilidad completa.

En Chile, la vinculación de la norma con el versari no es tan directa como lo fue para la doctrina española, básicamente por el art. 71. Esta disposición regula precisamente el supuesto en el que no se cumplan todos los requisitos del art. 10 $\mathrm{n}^{\circ} 8$ y señala que, si es así, "se observará lo dispuesto por el art. 490". El art. 490 castiga determinadas conductas imprudentes (delitos contra las personas cometidos con i m prudencia temeraria, pero también señala la pena para las otras figuras imprudentes en los arts. 491 y 492).

Si el caso fortuito incompleto supone la aplicación inmediata de las sanciones por conductas imprudentes ${ }^{32}$, tal determinación de responsabilidad se considera manifestación del versari. Así lo señalaba Rivacoba ${ }^{33}$ respecto de la imputación

culpa inconsciente se suele recurrir a la previsibilidad como posibilidad de conocer el resultado de peligro. Esta previsibilidad, se ha restringido por un deber de previsión. Para exigir este deber subjetivo, es importante reconocer un conocimiento básico respecto de la peligrosidad general de la conducta, como en VArgas, Tatiana; Perin, Andrea La "vidente" imputación imprudente. Peligrosidad de la conducta y consciencia del riesgo en la definición del dolo y la imprudencia, en Polit. Crim., 15/29 (2020), pp. 121 y ss.

${ }^{31}$ Art. 11 n 1 . "Son circunstancias atenuantes: $10^{\circ}$ Las expresadas en el artículo anterior, cuando no concurren todos los requisitos necesarios para eximir de responsabilidad en sus respectivos casos".

${ }^{32}$ Así, Del Río, Raimundo, Manual de derecho penal, (Santiago, Nascimento, 1947), p. 173; Labatut, Gustavo, Derecho penal. Parte general, (3 ${ }^{\mathrm{a}}$ ed., Santiago, Editorial Jurídica de Chile, 1958), p. 195.

${ }^{33}$ Rivacoba y Rivacoba, Manuel de (ed.), Actas de las Jornadas Internacionales de derecho penal en celebración del centenario del Código penal chileno (Valparaíso, Edeval, 1975), pp. 76-78. 
automática de la imprudencia. Sin embargo, esta admisión de responsabilidad no es aceptada en general por la dogmática nacional. Novoa ${ }^{34}$ la rechaza categóricamente y aclara que la observación del art. 71 supone una remisión que exige verificar los requisitos de la conducta imprudente. La sola exigencia de una acción ilícita no supondría per se una conducta imprudente. Por lo tanto, solo cabría responsabilidad penal si se dan sus presupuestos.

Hernánde $z^{35}$ considera inconveniente la existencia del art. $10 \mathrm{n}^{\circ} 8$ precisamente cuando la acción es ilícita, es decir, para el caso fortuito incompleto, como manifestación del versari. Sin embargo, esta crítica parece tener en cuenta una primera aproximación de Del Río, por una posible imputación a dolo, al considerar que el art. 71 solo procedía cuando faltaba dolo. Luego añade que la remisión al art. 71 complica, pero admite que la tesis dominante reclama la verificación de los requisitos de una conducta imprudente. Finalmente, rechaza la imputación por resultados imprevistos. Afirma que la norma del art. $10 \mathrm{n}^{\circ} 8$ no aporta un fundamento legal para hacer responsable sin culpa.

La admisión automática de responsabilidad se objeta al revisar la estructura de los tipos imprudentes, específicamente el art. 492 del Código Penal, e incluso luego de establecer la existencia de una imprudencia, por el art. $10 \mathrm{n}^{\circ} 13 \mathrm{del}$ mismo código. La primera norma suma a la conducta imprudente la exigencia de infracción de reglamentos. Por ella, con la infracción de reglamentos, $\mathrm{Novoa}^{36}$ evidencia que la existencia de una conducta ilícita, por la infracción de reglamentos, puede no implicar un comportamiento imprudente o descuidado. Requiere este elemento adicional.

La segunda disposición citada establece que las conductas imprudentes eximen en general de responsabilidad penal. El problema se presentaría respecto de los comportamientos culposos o imprudentes especialmente sancionados, que nos remite principalmente a los delitos contra las personas (en general, homicidios y lesiones) contemplados en las normas revisadas, arts. 490-492. El riesgo sería entender que en estos y otros especialmente punibles la admisión de la imprudencia es automática. Este no ha sido el caso, pues siempre se ha exigido comprobar la concurrencia de sus requisitos, aun en el art. 492 citado.

Es importante el análisis de los antecedentes legislativos históricos del caso fortuito. Cuando se incorporó en ese número 8 a nuestro Código Penal, en principio

${ }^{34}$ NovoA, Eduardo, Curso de derecho penal chileno. Parte general ( $3^{\mathrm{a}}$ ed., Santiago, Editorial Jurídica de Chile, 2005), I., pp. 502, 503 y 516. En general, ETCHEBERry, Alfredo, Derecho penal. Parte general, (3a ed., Santiago, Editorial Jurídica de Chile, 1998), I, pp. 329 ss.; Cury, Enrique, cit. (n. 67), pp. 343 y ss.; Garrido, Mario, cit. (n. 5), p. 233; Politoff, Sergio; Matus, Jean Pierre; Ramírez, María Cecilia, cit. (n. 5), p. 251; Matus, Jean Pierre; VAn Weezel, Alex, Comentario al artículo 71, en Politoff, Sergio; OrTiz, Luis, Texto y comentario del Código Penal chileno, (Santiago, Editorial Jurídica de Chile, 2002), p. 379); Hernández, Héctor, Art. 71, en Hernández, Héctor; Couso, Jaime (dirs.), Código penal comentado. Libro Primero (Arts. 1 a 105) (Santiago, Abeledo Perrot-LegalPublishing, 2011), pp. 622 y 623.

${ }^{35}$ Hernández, Héctor, Art. $10 n^{\circ} 8$, en Hernández, Héctor; Couso, Jaime (dirs.), Código Penal Comentado. Libro Primero (Arts. 1 a 105), cit. (n. 34), pp. 241-243; Él Mismo, Art. 71, cit. (n. 34), p. 622.

${ }^{36}$ NovoA, Eduardo, cit. (n. 34), pp. 502, 503 y 516. 
añadía también que el mal fuere causado "sin la menor culpa ni intención de causarlo"37. Solo se eliminó más adelante por estimarlo redundante ${ }^{38}$, específicamente respecto de la debida diligencia. Nunca se pensó en el versari como en España, al menos no se hizo en su interpretación objetiva aparentemente tradicional. Altamirano ${ }^{39}$, luego de revisar los comentarios de Pacheco, afirma que únicamente aceptaría su inclusión como eximente si se agregaba que "tocaría al reo probar su falta de intención". Fabres ${ }^{40}$ vincula la norma con una disposición de la ley romana que se refiere a la responsabilidad de un sujeto por todas las consecuencias de su crimen sin indagar acerca de cuál fue su intención. Sin embargo, no alude a imputaciones de resultado por acaso. De hecho, cita dos supuestos en los que alude a la realización de un delito distinto al que se propuso el sujeto o un mismo delito pero agravado. Propone la exclusión de esta circunstancia por su amplitud, al contemplar ambos supuestos. El problema es la definición del delito, no la desconexión de consideraciones subjetivas.

En el llamado caso fortuito incompleto no opera ciertamente la eximente del caso fortuito, aunque podría eximirse al agente de responsabilidad igualmente cuando la acción ilícita inicial no se realiza con infracción del deber de cuidado respecto del mayor resultado producido, que se causaría por accidente. Aparece aquí la relación con el voluntario accidental, con la hipótesis de la realización de una acción ilícita en sí misma y un acaso real; pero no como manifestación del versari comprendido en términos puramente objetivos. No ha sido así como se ha interpretado en Chile el caso fortuito incompleto, desde los orígenes del art. $10 \mathrm{n}^{\circ} 8$.

Si se aceptara la aplicación de semejante idea del versari, habría que admitir la responsabilidad penal por la sola realización de la conducta ilícita sin remitirse a exigencias de imprudencia, como lo dispone el legislador chileno y como se acepta dogmáticamente.

La determinación de una conducta imprudente respecto de las consecuencias más graves producidas remite al segundo supuesto de voluntario accidental. Es probable que ambos supuestos de voluntario accidental compartan ciertas exigencias de imputación subjetiva en esa referencia. De hecho, veremos que avalar imputaciones de efectos imprevisibles es difícilmente compatible con ideas del Aquinate. Si, en cambio, se mantiene una visión parcial de voluntario accidental que divide ambas alternativas, una objetiva y otra vinculada con la imprudencia, difícilmente puede sostenerse que las dos son formas de voluntario accidental equivalentes.

La relevancia de la imprudencia no termina de explicar por qué se establece como hipótesis de esa doctrina tomista, que, en los términos de Bascuñán ${ }^{41}$, afirma

\footnotetext{
${ }^{37}$ Comisión Redactora del Código Penal Chileno, Actas de las Sesiones (Santiago, Imprenta de la República, 1873), Sesión 6a 10 de mayo de 1870.

${ }^{38}$ Comisión Redactora del Código Penal Chileno, cit. (n. 37), Sesión 121, 24 de marzo de 1873 .

${ }^{39}$ Ibíd, Sesión 8a, 17 de mayo de 1870.

${ }^{40}$ Ibíd.

${ }^{41}$ Bascuñán, Antonio, cit. (n. 3), p. 229.
} 
la responsabilidad por resultados imprevistos. Podría contestarse, quizá, que se está refiriendo a la llamada imprudencia inconsciente o sin representación. Sin embargo, esta clase de conducta se vincula igualmente con exigencias de previsibilidad o, mejor aún, de cognoscibilidad ${ }^{42}$, por la realización de una conducta peligrosa conocida.

Especialmente interesante resulta un pasaje de Juan de Santo Tomás ${ }^{43}$, donde se ocupa de la imputación por daños producidos por una acción ilícita, con énfasis en el peligro que se sigue de ella y que explica la prohibición. "Y en esto se funda esta regla común: que si alguien se ocupa en una cosa ilícita [rei illicitae], esto es, prohibida para él [probibitae sibi], aun si emplea diligencia [adbibeat diligentiam], de seguirse un daño [damnum], se le imputa. Puesto que [esta persona], por el hecho mismo de ocuparse en una cosa ilícita, esto es, que está prohibida para él a causa del peligro de daño que [puede] seguirse [propter periculum damni secuturi], no actúa estando en su derecho [non utitur jure suo]; y así el daño que se sigue se estima [censetur] como voluntario en relación con él, por razón de tal prohibición y precepto. Removiéndose el precepto, sin embargo, no se estima como voluntario".

La parcelación del voluntario accidental tampoco explica por qué únicamente el primer caso, cuando se realiza una acción ilícita en sí misma, sería discutible (inconstitucional en el sentido de Bascuñán ${ }^{44}$ ) y supondría establecer responsabilidad por consecuencias imprevistas. Aparentemente, una acción ilícita cualquiera no es igual a una acción en sí misma ilícita. Falta mayor estudio a nivel jurídico sobre esta última conducta ${ }^{45}$, que puede apoyar todavía más el análisis del versari que se plantea aquí.

La responsabilidad por consecuencias imprevistas tampoco es equivalente a una imputación por resultados no buscados. El problema está en entender equivalentes ambas situaciones y en extender el versari a supuestos ni siquiera previsibles $^{46}$. Si bien este estudio no propone cuestionar esa comprensión del voluntario accidental, sí discute la interpretación objetiva general del versari in re illicita en el Derecho chileno, desde sus fuentes y con énfasis en la doctrina nacional.

\footnotetext{
${ }^{42}$ Aunque hay distintas concepciones sobre cognoscibilidad, se suele aludir a una suerte de desconocimiento evitable, que por el nivel de peligrosidad de la conducta se conecta con un deber de previsión. Así, ENGISCH, Karl, Die normativen Tatbestandselemente im Strafrecht, en Festschrift für Edmund Meager. Zum 70. Geburtstag, (Munich y Berlín, C. H. Beck, 1953), pp. 283 y ss.; JAKOBS, Günter, Estudios de derecho penal, (trad. castellana, Madrid, Civitas, 1997), pp. 172, 179-183; CoRCOY, Mirentxu, El delito imprudente (2a ed., Buenos Aires, B. de F., 2008), pp. 64, 94, 122-125, 209, 218 y ss.; Hava, E., La imprudencia inconsciente (Granada, Comares, 2002), pp. 207, 208, 214 y ss.

${ }^{43}$ Santo Tomás, Juan de, Cursus theologici. In Primam Secundae divi Thomae commentarii, (Matiscone, F. Protat, 1964), V, q. 6, d. 3, a. 3.

${ }^{44}$ Bascuñán, Antonio, cit. (n. 3), p. 230.

${ }^{45}$ Ciertamente, existen muchas investigaciones sobre la doctrina tomista; destacan comentarios escolásticos como los de BÁÑEZ, Domingo, Commentaria in secundam secundae angelici doctoris $d$. Thomae, quibus, quae ad fidem, spem, \& charitatem spectant, clarissime explicantur (Venetiis, Bernardum Iuntam, 1586); Lugo, Juan de, Disputationes scholasticae et morales. De justitia et jure (Parisiis, Ludovicum Vives, 1893) o Vío, Tomás de, cit. (n. 22). Sin embargo, falta enfrentar los aportes al plano jurídico-penal.

${ }^{46}$ Sobre esta extensión del versari a casos imprevisibles en la preterintención, advierte UAONDO, Juan de, cit. (n. 11), p. 64.
} 


\section{Reflexión dogmática ante otras manifestaciones del versari}

La exigencia que se realiza para el caso fortuito incompleto de un comportamiento imprudente respecto de los mayores efectos lesivos se condice con la usual aceptación de los delitos preterintencionales ${ }^{47}$ y el rechazo de los delitos cualificados por el resultado ${ }^{48}$. En los primeros, el aumento de pena por los efectos más graves se explica por una conducta culposa o imprudente; mientras que las figuras calificadas por el resultado son objetadas como forma de responsabilidad objetiva, que sería expresión del versari.

De hecho, tal distinción entre preterintención y cualificación por el resultado no es del todo clara. Praeterintención importa ir más allá de la intención. Se trata de una conducta dolosa que produce un resultado que excede lo buscado, que puede incluir la imprudencia y el acaso ${ }^{49}$. Remite a la expresión praeter intentionem empleada por santo Tomás para el obrar ${ }^{50}$ para aquello que está fuera de la intención, pero es más o menos previsto. En tal sentido, se vincula praeter intentionem con lo per accidens $^{51}$. Por su parte, hay nociones de cualificación por el resultado que aluden a exigencias de cuidado y al acaso ${ }^{52}$. También en Chile hay voces recientes que se pronuncian en semejante sentido. Matus y Ramírez ${ }^{53}$ conciben ahora el clásico ejemplo de preterintención, la violencia dolosa contra la mujer y aborto culposo o con dolo eventual, como delito calificado impropio.

$\mathrm{Ambos}^{54}$ examinan semejantes nociones para destacar que tras ellas se oculta

\footnotetext{
${ }^{47}$ Así, KünSEmülLer, Carlos, Las hipótesis preterintencionales, en Gaceta Jurídica, 204 (1997), p. 9. Esta noción que suele acoger la doctrina nacional se apoya especialmente en la influencia de los aportes de Finzi, Marcello, Il delitto preterintenzionale (Torino, F. Bocca, 1925). Con ella se desarrollaron doctrinas que vinculan la preterintención con una progresión de daños al mismo bien protegido jurídicamente o a bienes relacionados. Es probable que esta idea apoye también la vinculación subjetiva de la imprudencia con el mayor resultado producido.

${ }^{48}$ En general, Politoff, Sergio; Matus, Jean Pierre; Ramírez, María Cecilia, cit. (n. 4), pp. 250 y 251. Sin embargo, más tarde Matus, Jean Pierre; Ramírez, María Cecilia, Lecciones de derecho penal chileno. Parte especial (Thomson Reuters-La Ley, Santiago, 2014), I, p. 111, nota 58, consideran el delito de violencia dolosa contra la mujer y aborto culposo o con dolo eventual -usual ejemplo de preterintención-comodelito calificado impropio.

${ }^{49}$ De hecho, así se interpretaba la preterintención en el derecho español, con imprudencia y acaso, a partir de la antigua atenuante del art. 9, circunstancia 4a. Ver SánCHEZ-Tejerina, Isaías, cit. (n. 21), p. 302.

${ }^{50}$ Aquino, Tomás de, cit. (n. 19), II- II, q. 64, a. 7; c. II-II, q. 43, a. 3, c.; I-II, q. 72, a. 5, c.; II-II, q. 109, a. 2, ad 2.

${ }^{51}$ Miranda, Alejandro, El principio del doble efecto y su relevancia en el razonamiento jurídico, en Revista Chilena de Derecho, 35/3 (2008), p. 500.

${ }^{52}$ Boldova, Miguel Ángel, La imputación subjetiva de resultados "más graves" en el Código penal español, en ADPCP., 47/2 (1994), pp. 66-68, distingue los delitos calificados por el resultado de los cualificados por el resultado. Los primeros considerarían referencias culposas respecto de las mayores consecuencias producidas y los segundos exigirían derechamente dolo.

${ }^{53}$ Matus, Jean Pierre; Ramírez, María Cecilia, cit. (n. 21), p. 111, nota 58.

${ }^{54}$ Ambos, Kai, Preterintencionalidad y cualificación por el resultado, en InDret, 3 (2006), pp. 22 y 23. HormazÁBAL, Hernán, Imputación objetiva y subjetiva en los delitos cualificados por el resultado, en ADPCP., 42 (1989), pp. 1021 y 1022, se refiere a la estructura compleja de la cualificación por el resultado a partir del aborto con resultado muerte de la madre (antiguo art. 411 del CP espa-
} 
que el versari contiene una "idea correcta", que "quienes conocían y querían una conducta típica peligrosa, tendrán que responder por su falta de cuidado con relación al resultado". El versari estaría vinculado con una cualificación por el resultado que supone imprudencia. Ambos advierten la crítica que se hace a estos delitos calificados por el resultado por la punición de una sospecha, lo que supondría que el "versari subjetivizado" y el dolo indirecto "entrarían por la puerta de atrás".

La objeción no parece tan grave si se acoge una noción subjetiva del versari, a pesar de los riesgos de la posible imputación por sospecha, cuando supone imprudencia e incluso cierta clase de dolo. En todo caso, antes explican que el dolo general, el dolo indirecto y la culpa dolo determinata de Feuerbach se basan en el versar ${ }^{55}$, pero solo los dos primeros admiten una responsabilidad objetiva que excede la intención. La tesis de Feuerbach ${ }^{56}$ reclama imprudencia respecto de las mayores consecuencias lesivas, que se correspondería con la noción que la doctrina chilena acoge para los delitos preterintencionales ${ }^{57}$.

La declaración evidencia igualmente la conservación de una interpretación objetiva de versari, de la que se separaría la tesis de Feuerbach.

\section{LA RESPUESTA DEL VERSARI. CuestionAMIENTO DE LA CONCEPCiÓN} TRADICIONAL

La interpretación objetiva del versari in re illicita, el asignar todos los resultados que deriven de una ilicitud aun cuando fueren accidentales en términos de acaso ${ }^{58}$, se ha sostenido por años. Así ha ocurrido al menos en la doctrina continental ${ }^{59}$.

ñol), un delito doloso con otro culposo, que suele caracterizar a los delitos preterintencionales, al menos en nuestro medio.

${ }^{55}$ Ambos, Kai, cit. (n. 48), p. 3. UAONDO, Juan, cit. (n. 11), p. 48, habla del elemento psicológico del versari y afirma que las corrientes doctrinales que se vinculan más fuerte con esta máxima son las del dolo indirecto y la de la culpa dolo determinata.

${ }^{56}$ Feuerbach, Paul Johann Anselm, Lehrbuch des gemeinen in Deutschland gültigen peinlichen Rechts (Giessen, Georg Friedrich Heyer's Verlag, 1801), s 60.

${ }^{57}$ También se relaciona con los aportes de la doctrina italiana, destacados particularmente desde Finzi. Así, también se ha incluido en la preterintención formas de dolo indirecto, general, y una suerte de mixtura entre dolo y culpa, ver VELÁsQuez, Fernando, Derecho penal. Parte general (Santiago, Editorial Jurídica de Chile, 2011), pp. 805 y 806.

${ }^{58} \mathrm{Se}$ ha de advertir que la terminología es imprecisa, desde que refiere a lo causal, imprevisto e imprevisible, pero también a praeter intentionem, que contempla la previsión.

${ }^{59}$ STOOss, Carl, Lehrbuch des Österreichischen Strafrechts, (2 ${ }^{\mathrm{a}}$ ed., Wein und Leipzig, Franz Deuticke, 1913), pp. 93-95; VANnInI, Ottorino, Istituzioni di diritto penale. Parte generale, (Firenze, Carlo Cya, 1939), p. 139; DoLCINI, Emilio, Dalla responsabilità obbiettiva alla responsabilità per colpa: l'esperienza tedesca in tema di delitti qualificati dall'evento, en VAssalli, G. (a cura di), Problemi generali di diritto penale. Contibuto alla riforma (Milano, Giuffrè, 1982), pp. 255 y ss; Canestrari, Stefano, Dolo eventuale e colpa cosciente. Ai confini tra dolo e colpa nella struttura delle tipologie delittuose (Milano, Giuffrè, 1999) pp. 122 y ss.; ÉL MISMO, L'illecito penale preterintenzionale (Padova, Cedam, 1989), pp. 121 y ss., 151 y ss.; CARMONA, Angelo, Ilprincipio di personalità nell'ultima giurisprudenza della corte di cassazione: "colpa" o prevedibilità nel versari in re illicita, aspettando le sezioni unite, en Revista Penale, 4 (2009), pp. 501-509; KüPPER, Georg, ZurEntwicklung der erfolgsqualifizierten Delikete, en ZStW., 111 (1999), pp. 785 y ss.; Mezger, Edmund, Strafrecht. Ein Lebrbuch (3. Aufl., Berlin, München, von Duncker \& Humblot, 1949) pp. 247-250; ÉL MISMO, Die subjektiven Unrechtselemente, en GS., 89 
Hemos visto que la imputación por resultados consideraba tanto aquellos que no se buscaban como los imprevisibles ${ }^{60}$. En este sentido, se conecta también con una determinada comprensión de la doctrina del voluntario indirecto ${ }^{61}$, que parece hacer equivalente consecuencias no intentadas con consecuencias imprevistas y aun imprevisibles.

La conexión del versari con el caso fortuito no es del todo clara. El análisis de la doctrina italiana es especialmente relevante por los aportes relativos a la preterintención y a formas de imputación subjetivas m ix t a s (dolo y culpa). Destaca la primera concepción objetiva amplia de Carrara ${ }^{62}$. Sin embargo, posteriormente cambia de opinión sobre la imputación penal de resultados, pero no respecto de la noción objetiva de la máxima. Mantiene esta idea, sólo que declara injusto atribuir aquello que no es previsible ${ }^{63}$.

La mera primacía de la causalidad frente a la voluntad se presta para nociones

(1924), p. 205; JESCHECK, Hans-Heinrich, Wandlungen des strafrechtlichen Schuldbegriffs in Deutschland und Österreich, en Juristische Blätter, 120 (1998), pp. 609 y ss.; JAKOBS, Günter, Sobre la normativización de la dogmática jurídico-penal (Madrid, trad. cast., Thomson Civitas, 2003), pp. 79-81; Roxin, Claus, Strafrecht. Allgemeiner Teil, (München, C.H. Beck, 2006), I, \ 7, p. 223; CEREzo, José, cit. (n. 12), pp. 287 y 288; Cuello, Joaquín, El significado de la moderna teoría de la culpabilidad frente al concepto de delito en la tradición jurídico-penal española, en ADPCP., 49/I, (1996), pp. 842, 844; SiLva SÁnCHEZ, Jesús-María, Aproximación al derecho penal contemporáneo (Barcelona, J. M. Bosch, 1992), pp. 294296; Feijoo, Bernardo, Resultado lesivo e imprudencia (Barcelona, J. M. Bosch, 2001, pp. 199, 264 y 265; Bacigalupo, Enrique, Derecho penaly Estado de Derecho (México, Jurídica de las Américas, 2009), p. 113; SAndoval, Emiliano, Circunstancias eximentes de responsabilidad penal en el Código Penal Federal, (México, D.F., Jurídica de las Américas, 2012) p. 290; Castillo, Francisco, Principio de culpabilidady actio libera in causa. En defensa de su regulación legislativa, en La reforma del derecho penaly del derecho procesal penal en el Perú, Anuario de Derecho Penal 2009, (Lima, Fondo Editorial Pontificia Universidad Católica del Perú, 2011), p. 100; Zafaroni, Eugenio; Alagia, Alejandro; Slokar, Alejandro, Derecho penal. Parte general, (2 ed., Buenos Aires, Ediar, 2005) pp. 139-142; VeLÁsQueZ, Fernando, cit. (n. 32), pp. 168-171.

${ }^{60}$ En el Common Law se ha vinculado con la teoría causal de las condiciones, Hodgson, Douglas, Intervening Causation Law. Common Law, Civil Law and Comparative Law perspective (Saarbrücken, Lambert Academic Publishing, 2011), p. 343. También se trata como excepción al mens rea en los felony-murder y misdemeanor-manslanghter, KICHYUN RYU, Paul, The new Korean Criminal Code of October 3, 1953. An analysis of ideologies embedded in it, en Journal of Criminal Law, Criminology and Police Science, 48 (1953), pp. 282, 283; VAN DER VyVER, Johan, The International Criminal Court and the Concept of Mens Rea in International Criminal Law, en University of Miami International \& Comparative Law Review, 12 (2004), p. 73. Respecto de las exigencias subjetivas mínimas resulta del mayor interés la obra de Duff, Antony, Intention, Agency, and Criminal Liability: Philosophy of Action and Criminal Law, (Oxford, Blackwell, 1990). Para un examen general del sistema de imputación subjetiva Oxman, Nicolás, Una aproximación al sistema de imputación subjetiva en el Derecho penal anglosajón, en Ius et Praxis, 19 (2013), pp. 139-194.

${ }^{61} \mathrm{El}$ voluntario indirecto o voluntario in causa (según si es omisión o acción) remite en principio a la realización de una acción buena o indiferente de la que se sigue un efecto malo no directamente de la acción realizada, que el fin sea bueno y que haya proporcionalidad entre el efecto bueno y el malo. PARDo, Antonio, Sobre el acto humano: aproximación y propuesta, en Persona y Bioética, 12/2 (2008), pp. 86, 103-105. Sin embargo, el voluntario indirecto se ha asociado con formas de desconocimiento respecto del efecto malo, como apreciaremos desde algunas imprecisiones en Covarrubias o en la idea de per accidens.

${ }^{62}$ Carrara, Francesco, Programma. Parte generale, (3 ${ }^{a}$ ed., Lucca Tipografia Giusti, 1867), \ 270.

${ }^{63}$ Carrara, Francesco, Sul caso fortuito, en Opuscoli di Diritti Criminale, (1878), III, no 31, p. 15. 
objetivas del versari que integran también factores casuales. Luego se observa la exclusión del caso fortuito y, en general, de factores ajenos a la conducta con tesis restrictivas de la causalidad y con los posteriores desarrollos de la llamada teoría de la imputación objetiva (principalmente desde Honig ${ }^{64}$ en 1930 y Roxin en 1970). A partir de allí se ha consagrado una interpretación objetiva como los primeros canonistas, con criterios naturalistas y no normativos. El desarrollo de la imputación objetiva sumó estos últimos, que servirían de filtro ${ }^{65}$.

Los filtros normativos son fundamentales para restringir la imputación de riesgos jurídicamente relevantes que se realizan en el resultado. Estas restricciones podrían salvar las dificultades que una interpretación objetiva del versari suscita. Esto sería así si la imputación de conductas con la determinación de riesgos relevantes y la imputación de resultados mantuvieran consideraciones subjetivas, el conocimiento de la peligrosidad y de los peligros y lesiones producidas. Sin embargo, un excesivo normativismo ha llevado a descartar aspectos subjetivos no sólo de la imprudencia, sino también del dolo ${ }^{66}$, reducido a un juicio de atribución que no indaga en la voluntariedad de la acción. Semejante tendencia explica de algún modo la fuerza de la interpretación objetiva del versari. Analizaremos críticamente algunos de los antecedentes históricos de esta comprensión en general, que enfrentaremos luego al desarrollo de la dogmática nacional.

\section{Algunos antecedentes críticos}

La comprensión objetiva vigente incluso se ha vinculado con Suárez, específicamente a partir de referencias a estudios de Pereda ${ }^{67}$. También hay dudas sobre el nexo de tal comprensión con Pereda. Virto ${ }^{68}$ niega que su propuesta decida sobre la inclusión del principio en la antigua norma española del art. 8 $\mathrm{N}^{\circ} 8$, aunque admite que la disposición se presta para interpretaciones objetivas. Precisa que desde que Luzuriaga introduce la idea de culpa presunta de la ley de Partida por el actuar prohibido inicial, se admite el versari en los delitos culposos.

Es criticable cualquier interpretación objetiva fundada en Pereda. Éste se ocupa de la comprensión objetiva del versari y rechaza que ella proceda de los

\footnotetext{
${ }^{64} \mathrm{El}$ desarrollo actual de la tesis se inicia con sus estudios, pero desde consideraciones subjetivas, Honig, Richard, cit. (n. 22), pp. 115-120. Afirma que "el contenido del juicio de imputación dependerá de la originalidad teleológica de las actuaciones de voluntad humana". Específicamente sobre la consideración de factores subjetivos dentro del juicio de imputación objetiva como factor distintivo de lo fortuito, EsQuINAS, Patricia, ¿Sirve todavía para algo el principio de responsabilidad subjetiva? Hacia una nueva estructura del tipo penal, en Cuadernos de Política Criminal, 118 (2016), p. 194.

${ }^{65}$ Así, Cuello, Joaquín, cit. (n. 53), pp. 842, 844.

${ }^{66}$ Esta tendencia ya la advertía claramente CANCIO, Manuel, ¿Crisis del lado subjetivo del hecho?, en Cancio, Manuel; Caro, Dino, Estudios de derecho penal, Colección de Ciencias Penales (Lima, Palestra, 2010), II, p. 158.

${ }^{67}$ Ver ToRío, Ángel, "Versari in re illicita" y delito culposo. El denominado caso fortuito impropio, en $A D P C P ., 29 / 1$ (1976), p. 24.

${ }^{68}$ Virto, María José, El caso fortuito y la construcción del sistema de culpabilidad en el Código Penal de 1848 (Bilbao, Servicio Editorial Universidad del País Vasco, 1984), pp. 168-176, 330. Cerezo, José, cit. (n. 12), p. 288, también distingue a Pereda -junto con Jiménez de Asúa- como tesis distinta de la doctrina dominante respecto del versari, aunque sin mayor precisión.
} 
juristas españoles de los siglos XVI y XVII. Cuestiona incluso que tenga su base en las fuentes canónicas. Pereda ${ }^{69}$ explica que una concepción objetiva primitiva fue sostenida en el derecho germánico donde se desarrolló el derecho canónico, el que hubo de respetar sus nociones "para ir poco a poco neutralizando sus concepciones materialistas”. En todo caso, enseña que esto cambia drásticamente con juristas escolásticos españoles, específicamente Suárez ${ }^{70}$. Destaca que a Suárez no le basta la obra ilícita peligrosa (en orden al posible homicidio) si ha habido debido cuidado, pues nunca se le podrá imputar el homicidio.

No hay indicios de que la noción objetiva del versari se deba a Suárez, cuando él es especialmente crítico de las ideas de Covarrubias sobre lo v o l u n t a ri o por sus alcances objetivos ${ }^{71}$. No es admisible aquella concepción del versari con Suárez ${ }^{72}$ justamente cuando se preocupa por la restricción del homicidio vo l u n t a ri o en un caso complicado de lesiones que producen la muerte. A partir del ejemplo citado por Covarrubias de aquel que mandan a azotar y muere por el azotador encargado, Pereda considera casual el homicidio si la orden se asigna a una persona cuidadosa y se le dan instrucciones precisas. Él advierte, por otro lado, voluntad indire ct a si se manda a azotar sin encargo alguno para el azotador, aunque se señale como límite la muerte.

Es probable que la extensión vigente de semejante comprensión de la máxima provenga de la gravedad de su aplicación, con la imputación de resultados casuales $^{73}$. Así se explica la odiosa fama del versari. Canestrari ${ }^{74}$ habla del "perverso principio" y de la amenazante "vieja lógica" del versari, que conecta con el dolus generalis ${ }^{75}$. Es comprensible que la considere una lógica amenazante, cuando señala que puede llevar a entender que siempre han sido queridos los resultados de lesiones y muertes. Sin embargo, no parece tal si concluye que se trata de una "concreta previsión" de resultados.

En todo caso, se evidencia una mayor inclinación objetiva en los estudios de

${ }^{69}$ Pereda, Julián, cit. (n. 1), pp. 14-21, 23, muestra que el derecho penal nace en casi todos los pueblos de modo objetivo, a partir del resultado, y que el análisis subjetivo (p s i c o 1 ó g i c o ) "es fruto refinado del espíritu humano". Rosal, Juan del, Principios de derecho penal español, (Valladolid, Imprenta y Librería Casa Martín, 1945), I, pp. 214 y 215, no solo habla de un retroceso del derecho penal a una comprensión primitiva, sino que derechamente admite una "concepción jurídicoprivada" de derecho penal que supone responsabilidad por resultados.

${ }^{70}$ Pereda, Julián, cit. (n. 1), p. 111.

${ }^{71}$ Así lo destaca específicamente UAONDO, Juan de, cit. (n. 11), pp. 42 y 67.

${ }^{72}$ SuÁrez, Francisco, Commentaria in secundam secundae divi Thomae, scilicet de fide, de spe et de charitate disputationis, Opera omnia (Paris, Ludovicum Vivés, 1858).

${ }^{73}$ Varios casos cita Pereda, Julián, cit. (n. 1), pp. 20, 36-39, 43, 52-58, 66-68.

${ }^{74}$ Canestrari, Stefano, cit. (n. 12), pp. 77 y 93. En términos similares, Cury, Enrique, Derecho penal. Parte general, (7 ${ }^{\mathrm{a}}$ ed., Santiago, Ediciones Universidad Católica de Chile, 2005), p. 572 , habla de un "sentimiento de repugnancia natural" cuando considera desistimiento de la frustración si no se produce el resultado como manifestación del versari (i r r e s p o n s a b i lidad objetiva).

${ }^{75}$ Se vincula con esta noción de dolus generalis de Carpsov, como forma de imputación por dolo de un homicidio involuntario a raíz de una conducta dirigida a lesionar. Ver SANZ, Ángel, Aproximación al problema del denominado "dolus generalis", en InDret, 3 (2016), p. 4. 
Covarrubias $^{76}$, cuando se refiere al voluntario indirecto. Señala, como Aquino ${ }^{77}$, que "aquellos efectos que se siguen de un obrar, no pensados antes por el agente y que acontecen fuera de la intención, pero que se siguen per se y necesariamente de la acción o que, por lo menos, se siguen generalmente y suelen resultar de tal proceder, se imputan al agente". Agrega que “aquello casual que proviene de algún obrar fuera de la intención del agente y por él no previsto, se dice voluntario per accidens o querido por el actor, no per se y directamente". Entiende que esta voluntad puede ser más o menos indirecta si "la obra misma en sí considerada, sea más o menos apta u ordenada o peligrosa; para que se den aquellos resultados". En esta voluntad más o menos indirecta aparece la idea de peligrosidad de la conducta.

A pesar de la falta de previsión, con la peligrosidad de la conducta o tendencia general hacia el resultado no es tan evidente la determinación objetiva. Es cierto que la peligrosidad puede examinarse solo objetivamente, pero la ordenación o tendencia a la producción del resultado tiene sentido frente a la aptitud de la conducta si se conoce. Igualmente, la sola peligrosidad es vaga como factor de imputación y exigencias subjetivas.

Pereda $^{78}$ enseña que el concepto de lo voluntario de Covarrubias quedó impreciso, pues debió señalar qué entiende por per se y no per accidens. Destaca su relevancia para imputar el resultado, al cuestionar si " ¿ha de ser conocida y claramente prevista esa relación para que se me pueda imputar el efecto que se sigue, o basta que objetivamente se dé?”. Se decanta por una respuesta subjetiva de Covarrubias, aunque reconoce la tendencia objetiva de su estudio.

Tiene relevancia la distinción entre aquella voluntad, más o menos indirecta, y la doctrina del voluntario accidental, sobre todo cuando se trata de acciones por sí mismas ilícitas. Así, es interesante la consideración de la peligrosidad de la conducta para imputar por cosa ilícita que hacía Soto ${ }^{79}$. Expresaba que "se ha de entender aquella cosa que por su género suele ser causa de homicidio”. El límite no parece claro y la investigación del versari es relevante, si se establece como máxima de imputación.

Covarrubias funda el homicidio casual en el versari in re illicita. Este homicidio en principio parece per accidens y no debiera imputarse si está totalmente fuera de la intención, pero Covarrubias señala que el homicidio casual que sigue a un obrar ilícito debe imputarse si "tiende, por su misma naturaleza, a la lesión mortal o al homicidio". La idea parece recoger únicamente el nexo objetivo, pero vuelve a una conducta peligrosa que el agente asume y que de alguna manera conoce o debiera conocer.

\footnotetext{
${ }^{76}$ Covarrubias, Diego de, Opera omnia, De delictis et conatibus. Constitutionem si furiosus (Venecia, Relect., 1583), Parte II, pp. 532, 533, 535.

${ }^{77}$ Aquino, Tomás de, cit. (n. 19), I. II. q. 20, art. 3, reconoce voluntad indirecta respecto de resultados no intencionales, si per se y necesariamente se siguen del primer obrar o, por lo menos, es lo común y ordinario que se sigan.

${ }^{78}$ Pereda, Julián, cit. (n. 1), p. 489.

${ }^{79}$ Soto, Domingo de, De iustitia et iure (ed. bilingüe, Madrid, Instituto Estudios Políticos, 1967-1968), 1. 5, q. 1, a. 9 .
} 
Pereda ${ }^{80}$ destaca que Covarrubias y otros como Soto o Molina omiten una pregunta posterior por la tendencia de producción del resultado o peligrosidad, si es que basta esa tendencia objetiva o se requiere además una subjetiva. Por eso Pereda distingue a Suárez, quien sí se ocupa de consideraciones subjetivas. Afirma que, si en el obrar ilícito "se ha puesto toda aquella debida diligencia, es indudable que nos encontramos otra vez ante algo plenamente involuntario. $Y$ no se me diga que la obra, considerada en sí misma, era peligrosa; pues para el estudio de la responsabilidad se ha de considerar la obra en concreto, y si, en concreto, en estas circunstancias de tiempo y lugar, no se ve peligro alguno, no puede tampoco haber responsabilidad alguna, pues el resultado es completamente casual"81.

En el caso del maltrato a la mujer embrazada, es especialmente interesante la referencia que hace Azpilcueta ${ }^{82}$, al actuar s a bi e n d o que la puede poner en peligro probable de muerte y la falta de este peligro respecto del aborto no supone culpa, aunque se aborte. Rescata la idea de peligrosidad de la conducta y su conocimiento. También se ocupa de la conducta de la misma mujer embarazada, que requiere ser peligrosa si es que no tiene el propósito de abortar, para que haya culpa. La relevancia práctica de la máxima es indudable. A pesar de su objeción general por parte de la doctrina chilena, tampoco parece mantenerse del todo una visión objetiva del versari, según veremos a continuación.

\section{Mayores cuestionamientos desde la doctrina chilena}

La vinculación con el versari existe para imputar a una conducta ilícita resultados mayores a los buscados, pero su noción objetiva es criticable. Miranda ${ }^{83}$ advierte sobre la imprecisión de la tesis de Covarrubias y plantea restringir la imputación a los efectos previstos o al menos previsibles. Cita a Cathrein ${ }^{84}$, que en realidad conecta el versari exclusivamente con los efectos previstos. También la doctrina de Aquino no es del todo clara. Uaondo ${ }^{85}$ advierte que su tesis sigue en "líneas generales" el principio canónico, limitado al acto ilícito que es peligroso por su naturaleza y via quaedam ad homicidium. Estima que esta regla es todavía riesgosa, realizada la conducta dolosa, al no averiguar su relación con el resultado no querido.

Para lo que interesa en este examen, también en Chile parece sostenerse una compresión objetiva del versar ${ }^{86}$. Esta interpretación es la que funda su rechazo,

\footnotetext{
${ }^{80}$ Pereda, Julián, cit. (n. 1), p. 492.

${ }^{81}$ Ibíd.

${ }^{82}$ Azpilcueta, Martín de, Manual de confessores y penitentes (Salamanca, Casa de Andrea de Portonariis, Impresor de S. C. Magestad, 1556), p. 154.

${ }^{83}$ Miranda, Alejandro, El principio del doble efecto (Hildesheim -Zurich - New York, Olms, 2014), pp. 373 y 374, n. 945.

${ }^{84}$ Cathrein, Victor, Principios fundamentales de derecho penal (trad. castellana, Barcelona, Estudio filosófico-jurídico, 1911), p. 176.

${ }^{85}$ UAONDO, Juan de, cit. (n. 13), pp. 46-49.

${ }^{86}$ Cousiño, Luis, Derecho penal chileno (Santiago, Editorial Jurídica de Chile, 1975), I., pp. 878 y 880; NovoA, Eduardo, cit. (n. 34), pp. 502, 503 y 516; Etcheberry, Alfredo, Dolo y culpa, en Matus, Jean Pierre; Hernández, Héctor, Materiales de discusión presentados a la Comisión Foro Penal, Parte General, en Politica Criminal, 1 (2006), p. 54; NÁQuira, Jaime et al, Principios y penas en el derecho penal chileno, en RECPC., 10-r2 (2008), pp. 13-17, ÉL MISMO, Comentario al art. $10 n^{\circ} 8$,
} 
según vimos. Algunos aluden a la agravación por resultados como reflejo general deprincipios doctrinarios superados. En este sentido, Garrido ${ }^{87}$ menciona el problema y lo conecta con la época de dictación de nuestro Código Penal, análogo al Código español de 1848. Aunque no alude al versari, la relación parece clara, específicamente la del art. $10 \mathrm{n}^{\circ} 8$ con su par español del antiguo art. $8 n^{\circ} 8$. Ya vimos que en el origen de nuestra disposición no se mencionó la máxima y la preocupación no giró en torno a una responsabilidad por resultados, sino a la dificultad para determinar los ilícitos concurrentes.

Frente al caso español, es interesante tener presente el rechazo y consideraciones que hace Sánchez-Tejerina ${ }^{88}$, que se refiere a la antigua atenuante de preterintención del art. 9, $\mathrm{n}^{\circ} 4$ del Código Penal español, que contemplaría el exceso del daño tanto si es provocado imprudentemente como si se debe al caso (limitado al caso fortuito). Destaca que este caso no es punible si procede de un acto lícito. Revela que el problema se presenta cuando la acción es ilícita, que podría imputarse el exceso de resultado si se produce por caso fortuito. Sin hablar de versari, resuelve la dificultad rechazando la imputación. Objeta la mera causalidad y remite a la necesidad de que las consecuencias sean previstas o al menos previsibles para imputar por consecuencias. Al rechazo de interpretaciones meramente materiales suma criterios de proporcionalidad entre la conducta y el efecto producido, con interesantes pronunciamientos de la primera mitad del siglo XX.

La norma que posibilitaría el caso fortuito incompleto en Chile no ha supuesto admitir responsabilidad penal exclusivamente por los resultados más gravosos, al menos dogmáticamente. De modo independiente se ha mantenido una noción objetiva del versari, aunque es en realidad una visión global. No se ha dicho mucho sobre la máxima, probablemente por la comprensión objetiva que lleva a su rechazo inmediato. En general se objeta al examinar casos como el incendio con explosiones examinado o supuestos agravados de robo o secuestro ${ }^{89}$. Existen ciertas opiniones distintas que cuestionan tal concepción, aunque ella igualmente se considere y critique. Especial mención merece Solari, al igual que Rivacoba, por su influencia en el derecho nacional. Ambos parten de la concepción objetiva ${ }^{90}$, pero realizan importantes advertencias.

Solari ${ }^{11}$ admite en el versari "alguna medida de la culpabilidad" y reconoce que el repudio que genera proviene precisamente de la omisión de alguna forma de

en Politoff, Sergio; Ortiz, Luis, Texto y comentario del Código Penal chileno (Santiago, Editorial Jurídica de Chile, 2002), p. 146; Londoño, Fernando, El caso de la "la llave de gas del frustrado suicida-parricida", en VArgas, Tatiana (dir.), Casos destacados de derecho penal (Santiago, Thomson Reuters, 2015), p. 248, n. 74.

${ }^{87}$ Garrido, Mario, cit. (n. 6), p. 146.

${ }^{88}$ SÁnchez-Tejerina, Isaías, cit. (n. 21), pp. 302 y 303.

${ }^{89}$ Montealegre, Eduardo, La culpa en la actividad medica: imputación objetiva y deber de cuidado, en Revista Chilena de Derecho, 14 (1987), pp. 292 y 293, al proscribir la máxima en la actividad médica, cita un caso de la imputación de una muerte culposa a un médico si además se le atribuye las lesiones que sufre un pariente que se entera de su fallecimiento.

${ }^{90}$ Rivacoba y Rivacoba, Manuel de, cit. (n. 28), pp. 76-78; SOlari, Tito, Versari in re illicita, en Revista de Derecho, Pontificia Universidad Católica de Valparaíso, 1 (1977), pp. 252-254.

${ }^{91}$ SOLARI, Tito, cit. (n. 64), pp. 245, 252 y 253. 
culpabilidad en caso de resultados imprevisibles, como rasgo distintivo del caso fortuito. Antes, Rivacoba ${ }^{92}$ afirma que en el versari también se da la culpabilidad "de alguna manera", aunque se tenga por violación del principio de culpabilidad.

Estas ideas son coherentes con apreciaciones de Tomás de Aquino ${ }^{93}$ vinculadas con el versari, con la disminución del pecado subsecuente en la medida de que disminuye la voluntad: "Quia si ex actu illo praecedente subsecuta est ebrietas sine peccato, tunc peccatum sequens totaliter excusatur a culpa, sicut forte accidit de Lot. Si autem actus praecedens fuit culpabilis, sic non totaliter aliquis excusatur a peccato sequenti, quod scilicet redditur voluntarium ex voluntate praecedentis actus, inquantum scilicet aliquis, dans operam rei illicitae, incidit in sequens peccatum. Diminuitur tamen peccatum sequens, sicut et diminuitur ratio voluntarii".

Aparecen consideraciones subjetivas, aunque no se determinan sus alcances y modalidades. Sí cabe afirmar la exclusión de resultados imprevistos como puerta de entrada para el caso fortuito incompleto ${ }^{94}$. Falta examinar qué aspectos del principio de culpabilidad o, mejor, del principio de responsabilidad subjetiva, supone o supondría. La revisión de la clase de conducta ilícita (por sí misma), específicamente de su peligrosidad, es relevante para la determinación de aspectos subjetivos, si el sujeto previó o pudo prever los mayores efectos producidos.

En la práctica, en cambio, la noción objetiva del versari se mantiene y por eso se cuestiona en general. Por tal razón es rechazado como manifestación de responsabilidad objetiva. Sin embargo, las situaciones en las que se resuelven conflictos por la producción de resultados más graves son frecuentes, especialmente en el caso de delitos de lesiones que producen la muerte ${ }^{95}$. Es interesante la observación que hace Etcheberry ${ }^{96}$ en la Comisión del Foro Penal para la discusión del anteproyecto de Código Penal en 2003, respecto de los problemas de preterintención. Estima aceptable la respuesta por concursos de delitos, antes que el empleo de delitos cualificados por el resultado y los casos de versari, pero se preocupa por situaciones donde existen resultados mayores en las que el delito doloso base no alcanza una entidad propia. Se entiende que no alcanzaría a configurar un delito. Su preocupación no es muy distinta a la de los comisionados que intervinieron en el origen del art. $10 \mathrm{n}^{\circ}$ 8, específicamente Fabres ${ }^{97}$. El problema era de delimitación y parecía desconectarse del versari.

Los casos prácticos parecen esconder igualmente las dificultades de imputación de resultados más graves que los buscados por una conducta ilícita. El problema interesa también en el derecho anglonorteamericano, que recurre a la d o c $\mathrm{t}$ r i n a del delit o menor (lesser crime doctrine), específicamente con advertencia del

\footnotetext{
${ }^{92}$ Rivacoba y Rivacoba, Manuel de, cit. (n. 28), pp. 54 y 55.

${ }^{93}$ Aquino, Tomás de, cit. (n. 19), II-II, q. 150 a. 4 co.

${ }^{94}$ Ciertos antecedentes ya en Vargas, Tatiana, cit. (n. 5), pp. 369-373.

${ }^{95}$ No deja de llamar la atención que las necesidades prácticas motivaron el origen del casus (todo aquello que excede de la intención) en el derecho romano, cuando se centra en el desarrollo de consideraciones subjetivas. Ver MARTos, Juan Antonio, El principio de responsabilidad subjetiva, en Revista de Derecho Penal y Criminología, 6 (1996), pp. 814 y 815.

${ }^{96}$ ETCHEBERRY, Alfredo, cit. (n. 79), p. 54.

${ }^{97}$ Comisión Redactora del Código Penal Chileno, cit. (n. 32), Sesión 8a 17 de mayo
} de 1870. 
principio medieval ${ }^{98}$. La preocupación por excesos existe y se recurre a la doctrina del p r o pó s i to c o m ú n (common purpose doctrine) para imputar al partícipe y resolver el problema. En esta doctrina destacan consideraciones subjetivas (propósito), interpretadas de distintos modos en el derecho norteamericano y en el inglés: como riesgo razonablemente previsible o la advertencia de algún riesgo. Sanford ${ }^{99}$ critica ambas interpretaciones por recurrir a una mera negligencia, suficiente para imputar responsabilidad civil o incluso menor. Objeta la imputación sin exigir los elementos de culpabilidad que el crimen requiere.

Las exigencias para imputar conductas y establecer responsabilidad penal son distintas. De allí que se cuestione cualquier admisión de responsabilidad objetiva. Las dudas sobre una interpretación objetiva del versari provienen de las propias referencias canónicas, al igual que de los aportes de juristas escolásticos, como Suárez ${ }^{100}$.

Es cuestionable que la interpretación objetiva provenga de su origen canónico, en el siglo XII ${ }^{101}$, por el énfasis en la necesidad de un comportamiento voluntario, que exige imputación a dolo y culpa para sancionar. Así, el canon 2.199 Código de Derecho Canónico de 1917: "Imputabilitas delicti pendet ex dolo delinquentis vel ex eiusdem culpa in ignorantia legis violatae aut in omissione debitae diligentiae; quare omnes causae quae augent, minuunt, tollunt dolum aut culpam, eo ipso augent, minuunt, tollunt delicti imputabilitatem".

Uaondo $^{102}$ revela que el principio no fue unánimemente aceptado por los canonistas, aunque advierte que no ha de extrañar la existencia de interpretaciones que lleguen a las últimas consecuencias, al incluir el caso fortuito para imputar. En los documentos canónicos medievales ya se ve la tensión entre el versari y las enseñanzas de las Escrituras, como la muerte casual de un sujeto por su amigo cuando van a cortar leña al bosque y salta el hierro del hacha sin advertirlo (caso Deuteronomio, capítulo XIX, que salva la vida del ho micida fugitivo). Pereda ${ }^{103}$ los muestra como resabios del derecho bárbaro. En el derecho canónico se establecieron ciertas penitencias con atención a la responsabilidad por la causa ${ }^{104}$, pero no es claro que se hayan dispuesto castigos civiles o penales sobre la base de este principio. Incluso se ha advertido una contradicción en su interpretación objetiva con el espíritu humanitario de la Iglesia ${ }^{105}$.

Atribuir carácter voluntario a toda causación de resultados que provenga de

\footnotetext{
${ }^{98}$ El versari se presenta como excepción a la regla de culpabilidad (fault), junto con la responsabilidad objetiva (strict liability).

${ }^{99}$ SANFORD, Kadish, Reckless complicity, en Journal of Criminal Law and Criminology, 87/2 (1997), pp. 5 y 7.

${ }^{100}$ Además de las observaciones hechas, RodríGuez Mourullo, Gonzalo, cit. (n. 16) p. 287, advierte que la ventana abierta en el llamado caso fortuito incompleto se debe a la vigencia del principio en su sentido literal y no la interpretación de estos juristas.

${ }^{101}$ Recordemos que su origen se ha remontado a fechas previas, al s. XI.

${ }^{102}$ UAONDO, Juan de, cit. (n. 11), pp. 44 y 45.

${ }^{103}$ PeredA, Julián, cit. (n. 1), pp. 25-68.

${ }^{104}$ Ver Concilio Acyrano, c. 22, Decreto de Graciano, D. 50 c. $42,43$.

${ }^{105}$ Así, Huerta, Antonio, La relación de causalidad en la teoría del delito (Madrid, Ministerio de Justicia. Consejo Superior de Investigaciones Científicas, 1948), p. 241.
} 
una conducta voluntaria inicial, aunque haya consecuencias accidentales o no intentadas por el agente, es una ficción que pugna con la tradición de juristas escolásticos, marcada por estudios de santo Tomás de Aquino. Aunque Tomás de Aquino trata el punto de manera tan general que parecería favorecer la concepción objetivista del versari, ésta es incompatible con sus principios generales acerca de la responsabilidad moral y la culpabilidad.

\section{PRINCIPALES CONCLUSIONES}

El caso fortuito incompleto representa o abre la puerta a la manifestación más clara de la concepción objetiva del versari in re illicita. Es especialmente relevante en Chile por la regulación del art. $10 \mathrm{n}^{\circ} 8$ del Código Penal chileno; pero principalmente por la importancia de los casos que se presentan en la práctica, por el riesgo de imputar resultados más graves producidos por una conducta ilícita, aun cuando fueren imprevistos.

El examen de este caso y de la máxima no supone revivir una discusión muerta. Es cierto que en el origen de la disposición citada nunca se pensó en imputar resultados por acaso o imprevisión. Tampoco su interpretación posterior ha generado dudas sobre la posible admisión de semejante imputación. Igualmente, la concepción objetiva de versari se mantiene, aunque es objetada.

Sin embargo, destacan opiniones en Chile que no siguen tal comprensión de la máxima. Se acogen apreciaciones subjetivas y, con ello, se rechaza el acaso como supuesto de imputación por versari. El problema es que tales consideraciones se conectan con la imprudencia, al igual que con la calificación por el resultado y la preterintención. Todavía existen imprecisiones por resolver.

Por ejemplo, es fundamental distinguir la clase de ilicitud, si se infringen normas penales o no, y el nivel de peligrosidad de la conducta ilícita respecto de los bienes finalmente afectados. Una acción ilícita cualquiera no supone una ilicitud penal. La responsabilidad por consecuencias imprevistas tampoco es equivalente a una imputación por resultados no buscados. El problema está en equiparar ambas situaciones y en extender el versari a supuestos ni siquiera previsibles

No es clara la interpretación objetiva del versari en la doctrina chilena, como parece ocurrir en la práctica. Si bien esta acepción sirve para descartar su consideración, muchos casos parecen admitirla sin mayor cuestionamiento. Se plantea aquí que redescubrir el sentido de esta máxima tiene importantes alcances a la hora de resolver problemas frecuentes con base en criterios de imputación objetiva si olvidan consideraciones subjetivas en la imputación normativa de conducta humanas. Los filtros valorativos jurídicos son necesarios. El riesgo se presenta ante la primacía actual de desarrollos normativos que retornan a determinaciones puramente objetivas. 


\section{BIBLIOGRAFÍA}

Ambos, Kai, Preterintencionalidad y cualificación por el resultado, en InDret, 3 (2006), 38 pp. Aquino, Tomás de, Opera Omnia, (1556), en http:/ / wnww.corpusthomisticum.org/ iopera.btml AzPilcueta, Martín de, Manual de confessores y penitentes (Casa de Andrea de Portonariis, Impresor de S. C. Magestad, Salamanca, 1556).

Bacigalupo, Enrique, Derecho penal y Estado de Derecho (México, Jurídica de las Américas, 2009).

Bascuñán, Antonio, Comentario. Corte Suprema, 20 de noviembre de 1997, en Revista de Derecho y Jurisprudencia y Gaceta de los Tribunales, 3 (1997), pp. 219-231.

BÁÑEz, Domingo, Commentaria in secundam secundae angelici doctoris d. Thomae, quibus, quae ad fidem, spem, \& charitatem spectant, clarissime explicantur (Venetiis, Bernardum Iuntam, 1586).

Boldova, Miguel Ángel, La imputación subjetiva de resultados "más graves” en el Código penal español, en ADPCP., 47/2 (1994), pp. 55-79.

Cancio, Manuel, ¿Crisis del lado subjetivo del hecho?, en Cancio, Manuel; Caro, Dino, Estudios de Derecho penal, Colección de Ciencias Penales (Lima, Palestra, 2010), II, pp. 153-179.

Canestrari, Stefano, L'illecito penale preterintenzionale (Padova, Cedam, 1989).

-Dolo eventuale e colpa cosciente. Ai confini tra dolo e colpa nella struttura delle tipologie delittuose (Milano, Giuffrè, 1999).

- La estructura del dolo eventual y las nuevas fenomenologías de riesgo (trad. castellana), en Anales de Derecho, 23 (2004), pp. 59-95.

CARMona, Angelo, Il principio di personalità nell'ultima giurisprudenza della corte di cassą̧ione: "colpa" o prevedibilità nel versari in re illicita, aspettando le sezioni unite, en Revista Penale, 4 (2009), pp. 501-509.

Carrara, Francesco, Opuscoli di Diritto Criminale (Lucca, 1870), I.

- Programma. Parte generale, (3 ${ }^{a}$ ed., Lucca, Tipografia Giusti, 1867).

— Sul caso fortuito, en Opuscoli di Diritti Criminale (1878), II, $\mathrm{n}^{\circ} 31$.

Castillo, Francisco, Principio de culpabilidady actio libera in causa. En defensa de su regulación legislativa, en La reforma del derecho penal y del derecho procesal penal en el Perú, Anuario de Derecho Penal 2009, (Lima, Fondo Editorial Pontificia Universidad Católica del Perú, 2011).

Cathrein, Víctor, Principios fundamentales de Derecho penal (trad. castellana, Barcelona, Estudio filosófico-jurídico, 1911).

Cerezo, José, El versari in re illicita y el párrafo tercero del, artículo 340 bis a del Código Penal español, en ADPCP., 23 (1970), pp. 287-300.

Comisión Redactora del Código Penal Chileno, Actas de las Sesiones (Santiago, Imprenta de la República, 1873).

Corcoy, Mirentxu, El delito imprudente ( $2^{\mathrm{a}}$ ed., Buenos Aires, B. de F., 2008).

Cousiño, Luis, Derecho penal chileno (Santiago, Editorial Jurídica de Chile, 1975).

Covarrubias, Diego de, Opera omnia, De delictis et conatibus. Constitutionem si furiosus. (Venecia, Relect., 1583), Parte II.

CuelLo, Joaquín, El significado de la moderna teoría de la culpabilidad frente al concepto de delito en la tradición jurídico-penal española, en ADPCP., $49 / 1$ (1996), pp. 837-862.

Cury, Enrique, Derecho penal. Parte general ( $7^{\mathrm{a}}$ ed., Santiago, Ediciones Universidad Católica de Chile, 2005).

Del Río, Raimundo, Manual de derecho penal (Santiago, Nascimento, 1947). 
DolCINI, Emilio, Dalla responsabilità obbiettiva alla responsabilità per colpa: l'esperienza tedesca in tema di delitti qualificati dall'evento, en AA.VV., Problemi generali di diritto penale - Contributo alla riforma, a cura di G. Vassalli (Milano, Giuffré, 1982), pp. 255-292.

Duff, Antony, Intention, Agency, and Criminal Liability: Philosophy of Action and Criminal Law, (Oxford, Blackwell, 1990).

Engisch, Karl, Die normativen Tatbestandselemente im Strafrecht, en Festschrift für Edmund Mezger. Zum 70. Geburtstag (Munich y Berlín, C. H. Beck, 1953).

EsQuinas, Patricia, ¿Sirve todavía para algo el principio de responsabilidad subjetiva? Hacia una nueva estructura del tipo penal, en Cuadernos de Politica Criminal, 118 (2016), pp. 185-236.

Etcheberry, Alfredo, Dolo y culpa, en Matus, Jean Pierre; Hernández, Héctor, Materiales de Discusión presentados a la Comisión Foro Penal, Parte General, en Política Criminal, 1 (2006), pp. 51-54.

—Derecho penal. Parte general (3a ed., Santiago, Editorial Jurídica de Chile, 1998), I.

Feuerbach, Paul Johann Anselm, Lehrbuch des gemeinen in Deutschland gültigen peinlichen Rechts (Giessen, Georg Friedrich Heyer's Verlag, 1801).

FInZI, Marcello, Il delitto preterintenzionale (Torino, F. Bocca, 1925).

Gardner, Martin, The Mens Rea Enigma: Observations on the Role of Motive in the Criminal Law Past and Present, en Utab L. Rev., 3 (1993), pp. 635-750.

Garrido, Mario, Derecho penal. Parte general ( $4^{\mathrm{a}}$ ed., Santiago, Editorial Jurídica de Chile, 2005), II.

—Derecho penal. Parte especial, (4a ed., Santiago, Editorial Jurídica de Chile, 2010), III.

Hernández, Héctor, Art. $10 n^{\circ}$ 8, en Hernández, Héctor; Couso, Jaime (dirs.), Código Penal Comentado. Libro Primero (Arts. 1 a 105) (Santiago, Abeledo PerrotLegalPublishing, 2011), pp. 239-243.

- Art. 71, en Hernández, Héctor; Couso, Jaime (dirs.), Código Penal Comentado. Libro Primero (Arts. 1 a 105) (Santiago, Abeledo Perrot-LegalPublishing, 2011), pp. 621-623.

Hodgson, Douglas, Intervening Causation Law. Common Law, Civil Law and Comparative Law perspective, (Saarbrücken, Lambert Academic Publishing, 2011).

Honig, Richard, Causalidad e imputación objetiva, en SAnCINETTI, Marcelo (comp.), Causalidad, riesgo e imputación (trad. castellana, Buenos Aires, Hammurabi, 2009), pp. 105-143.

HormazÁBAL, Hernán, Imputación objetiva y subjetiva en los delitos cualificados por el resultado, en ADPCP., 42 (1989), pp. 1021-1050.

Huerta, Antonio, La relación de causalidad en la teoría del delito (Madrid, Ministerio de Justicia. Consejo Superior de Investigaciones Científicas, 1948).

JAKOBS, Günter, Estudios de derecho penal (trad. castellana, Civitas, Madrid, 1997).

— Sobre la normativización de la dogmática jurídico-penal (trad. cast., Madrid, Thomson Civitas, 2003).

Jescheck, Hans-Heinrich; WeIgend, Thomas, Lehrbuch des Strafrechts: Allgemeiner Teil (Berlín, Duncker \& Humboldt, 1996).

JESCHECK, Hans-Heinrich, Wandlungen des strafrechtlichen Schuldbegriffs in Deutschland und Österreich, en Juristische Blätter, 120 (1998), pp. 609-618.

KÜNSEMÜLLER, Carlos, Las hipótesis preterintencionales, en Gaceta Jurídica, 204 (1997), pp. $7-12$.

KüPPER, Georg, Zur Entwicklung der erfolgsqualifizierten Delikte, en ZStW., 111 (1999), pp. 785 y ss. 
KuTTNER, Stephan, Kanonistische Schuldlehre von Gratian bis auf die Dekretalen Gregors IX.: Systematisch auf Grund der Quellen handschriftlichen dargestellt (Città del Vaticano, 1935).

Kichyun Ryu, Paul, The new Korean Criminal Code of October 3, 1953. An analysis of ideologies embedded in it, en Journal of Criminal Law, Criminology and Police Science, 48 (1953), pp. 275-295.

Labatut, Gustavo, Derecho penal. Parte general, ( $3^{a}$ ed., Santiago, Editorial Jurídica de Chile, 1958).

LONDOÑo, Fernando, El caso de la "la llave de gas del frustrado suicida-parricida", en VARGAS, Tatiana (dir.), Casos destacados de derecho penal (Santiago, Thomson Reuters, 2015), pp. 149-151.

Lugo, Juan de, Disputationes scholasticae et morales. De justitia et jure (Parisiis, Ludovicum Vives, 1893).

Martos, Juan Antonio, El principio de responsabilidad subjetiva, en Revista de Derecho Penal y Criminología, 6 (1996), pp. 783-857.

Matus, Jean Pierre; Ramírez, María Cecilia, Lecciones de derecho penal chileno. Parte especial (Santiago, Thomson Reuters-La Ley, 2014).

Matus, Jean Pierre; Van Weezel, Alex, Comentario al artículo 71, en Politoff, Sergio; Ortiz, Luis, Texto y comentario del Código Penal chileno (Santiago, Editorial Jurídica de Chile, 2002), pp. 323-382.

Mezger, Edmund, Strafrecht. Ein Lebrbuch (3. Aufl., Berlin, München, von Duncker \& Humblot, 1949) pp. 247-250.

—Die subjektiven Unrechtselemente, en GS., 89 (1924), pp. 205 y ss.

Miranda, Alejandro, Elprincipio del doble efecto y su relevancia en el razonamiento jurídico, en Revista Chilena de Derecho, 35/3 (2008), pp. 485-519.

—El principio del doble efecto (Olms, Hildesheim -Zurich - New York, 2014).

Montealegre, Eduardo, La culpa en la actividad medica: imputación objetiva y deber de cuidado, en Revista Chilena de Derecho, 14 (1987), pp. 259-311.

NÁQuira, Jaime; et al, Principios y penas en el derecho penal chileno, en RECPC., 10-r2 (2008), 71 pp.

- Comentario al art. $10 n^{\circ} 8$, en Politoff, Sergio; Ortiz, Luis, Texto y comentario del Código Penal chileno (Santiago, Editorial Jurídica de Chile, 2002).

NovoA, Eduardo, Curso de derecho penal chileno. Parte general ( $3^{\mathrm{a}}$ ed., Santiago, Editorial Jurídica de Chile, 2005), I.

Ossandón, Magdalena, La intención de dar muerte al feto y su relevancia para la imputación objetiva y subjetiva en el delito de aborto, en Revista de Derecho, Universidad Católica del Norte, 2 (2011), pp. 103-136.

PAPIENSE, Bernardo, Summa Decretalium (Ratisbonae, 1860).

Oxman, Nicolás, Una aproximación al sistema de imputación subjetiva en el derecho penal anglosajón, en Ius et Praxis, 19 (2013), pp. 139-194.

Pardo, Antonio, Sobre el acto bumano: aproximación y propuesta, en Persona y Bioética, 12/2 (2008), pp. 78-107.

Pereda, Julián, El 'versari in re illicita' en la doctrina y en el Código Penal. Solución suareciana (Madrid, Reus, 1948).

Pessina, Enrique, Elementos de derecho penal (trad. cast., Madrid, Imprenta de la Revista de la Legislación, 1892).

Polanco, Daniel, Estudio sobre la agravante del articulo 72 del Código Penal: Prevalerse de un menor de edad. Análisis de sus elementos y aplicación, en Polít. crim., 10/20, (2015), pp. 597-621. 
Politoff, Sergio; Matus, Jean Pierre; Ramírez, María Cecilia, Lecciones de derecho penal. Parte especial, (2a ed., Santiago, Editorial Jurídica de Chile, 2006).

—Lecciones de derecho penal. Parte general (Santiago, Editorial Jurídica de Chile, 2004).

Politoff, Sergio; Grisolía, Francisco; Bustos, Juan, Derecho penal. Parte especial.

Delitos contra el individuo en sus condiciones físicas, $\left(2^{\mathrm{a}}\right.$ ed., Santiago, Editorial Jurídica Congreso, 2006).

Rivacoba y Rivacoba, Manuel de (ed.), Actas de las Jornadas Internacionales de Derecho Penal en Celebración del Centenario del Código Penal Chileno (Valparaíso, Edeval, 1975).

Rodríguez, Luis; De la Fuente, Felipe, El principio de culpabilidad en la Constitución de 1980, en Revista de Derecho de la Universidad Católica de Valparaíso, 13 (1989-1990) pp. 125-153.

Rodríguez Mourullo, Gonzalo, Hacia una nueva interpretación de la eximente del caso fortuito, en ADPCP., 16 (1963), pp. 273-302.

Rosal, Juan del, Principios de derecho penal español (Valladolid, Imprenta y Librería Casa Martín, 1945), I.

Roxin, Claus, Strafrecht. Allgemeiner Teil (München, C.H. Beck, 2006), I.

SÁnchez-Tejerina, Isaías, Derecho penal español ( $5^{a}$ ed., Madrid, Imprenta y Litografía Juan Bravo, 1950), I.

SANFORD, Kadish, Reckless complicity, en Journal of Criminal Law and Criminology, 87/2 (1997), 25 pp.

SANZ, Ángel, Aproximación al problema del denominado "dolus generalis", en InDret, 3 (2016), 25 pp.

Sandoval, Emiliano, Circunstancias eximentes de responsabilidad penal en el Código Penal Federal, (México, D.F., Jurídica de las Américas, 2012).

Santo Tomás, Juan de, Cursus theologici. In Primam Secundae divi Thomae commentarii (Matiscone, F. Protat, 1964).

Silva SÁnchez, Jesús-María, Aproximación al derecho penal contemporáneo, (Barcelona,J. M. Bosch, 1992).

Solari, Tito, Versari in re illicita, en Revista de Derecho Pontificia Universidad Católica de Valparaiso, 1 (1977), pp. 245-265.

Soto, Domingo de, De iustitia et iure, (Madrid, Edición bilingüe, Instituto Estudios Políticos, 1967-1968).

STOOss, Carl, Lebrbuch des Österreichischen Strafrechts, (2 $2^{\mathrm{a}}$ ed., Wein und Leipzig, Franz Deuticke, 1913).

SuÁrez, Francisco, Commentaria in secundam secundae divi Thomae, scilicet de fide, de spe et de charitate disputationis, Opera omnia (Paris, Ludovicum Vivés, 1858).

Torres, Javiera, Delito de abandono de personas desvalidas, en Revista de Derecho de la Pontificia Universidad Católica de Valparaíso, 43/2 (2014), pp. 261-294.

Torío, Ángel, "Versari in re illicita" y delito culposo. El denominado caso fortuito impropio, en ADPCP., 29/1 (1976), pp. 17-44.

UAOndo, Juan de, La preterintencionalidady el "Codex Iuris Canonici", en Revista Española de Derecho Canónico, 7/19 (1952), pp. 41-73.

VAn der Vyver, Johan, The International Criminal Court and the Concept of Mens Rea in International Criminal Law, en University of Miami International \& Comparative Law Review, 12 (2004), pp. 57-150.

Vannini, Ottorino, Istituzioni di diritto penale. Parte generale (Firenze, Carlo Cya, 1939).

Vargas, Tatiana, Delitos de peligro abstracto y resultado. Determinación de la incertidumbre penalmente relevante, (Thomson-Aranzadi, Pamplona, 2007). 
- Algunos antecedentes sobre el complejo "deber de previsión" médico, en Revista de Derecho, 30/1 (2017), pp. 351-375.

Vargas, Tatiana; Perin, Andrea La "vidente" imputación imprudente. Peligrosidad de la conducta y consciencia del riesgo en la definición del dolo y la imprudencia, en Polit. Crim., 15/29 (2020), pp. 111-140.

Velásquez, Fernando, Derecho penal. Parte general (Santiago, Editorial Jurídica de Chile, 2011).

Vío, Tomás de (Cayetano), Commentarium in Summa S. Thomae, en Angelici Doctoris S. Thomae Aquinatis, Summa theologica, cum commentariis Thomae de Vio Card. Cajetani, et elucidationibus litteralibus P. Seraphini Capponi a Porrecta, (Roma, s./ed., 1773).

VIRTO, María José, El caso fortuito y la construcción del sistema de culpabilidad en el Código Penal de 1848, (Bilbao, Servicio Editorial Universidad del País Vasco, 1984).

VON BAR, Carl, Gesetz. und Schuld (Berlín, Guttentag, 1907).

Zafaroni, Eugenio; Alagia, Alejandro; Slokar, Alejandro, Derecho penal. Parte general, ( $2^{\mathrm{a}}$ ed., Buenos Aires, Ediar, 2005). 